\title{
A mixed-type intraductal papillary mucinous neoplasm of the pancreas with a histologic combination of gastric and pancreatobiliary subtypes in a 70-year-old woman: a case report
}

\author{
Sawsan Ismail ${ }^{1 *}$, Rama Darwisho², Mohammed Ali $^{3}$, Maen Haidar ${ }^{4}$, Mohammad Adib Houreih $^{5}$ and
} Zuheir Alshehabi ${ }^{1}$

\begin{abstract}
Background: Intraductal papillary mucinous neoplasms are rare papillary pancreatic neoplasms arising from major pancreatic ducts, characterized by duct dilation and mucin secretion. They comprise approximately $1 \%$ of all exocrine neoplasms and are classified according to their anatomical sites into main duct-type, branch duct-type, and mixed-type intraductal papillary mucinous neoplasms. Histological examination plays a crucial role in distinguishing and classifying intraductal papillary mucinous neoplasms into gastric, intestinal, pancreatobiliary, and oncocytic subtypes.

Case presentation: We present the case of a 70-year-old Syrian woman who was admitted to our hospital due to an intermittent epigastric pain accompanied by diarrhea and weight loss with a recent diagnosis of diabetes mellitus. Following clinical, laboratory, and radiological examination, distal pancreatectomy involving the body and the tail of the pancreas was performed. Interestingly, histological examination of the resected specimens revealed the diagnosis of a mixed-type intraductal papillary mucinous neoplasm with a unique combination of gastric and pancreatobiliary subtypes.

Conclusion: To the best of our knowledge, the combination of multiple histological subtypes of intraductal papillary mucinous neoplasms has been recorded in a few studies with reference to the challenging histological detection. Herein, we report a rare case with a significant histological combination, highlighting the difficulties in differential diagnosis due to the absence of ancillary techniques, with a brief review on diagnostic methods, histological characteristics and surgical recommendations.
\end{abstract}

Keywords: Intraductal papillary mucinous neoplasm, Mixed-type IPMN, Endoscopic retrograde cholangiopancreatography, Gastric and pancreatobiliary subtypes, Distal pancreatectomy

\footnotetext{
* Correspondence: sawsanismail8@gmail.com

'Department of Pathology, Cancer Research Center, Faculty of Medicine,

Tishreen University, Lattakia, Syria

Full list of author information is available at the end of the article
}

(c) The Author(s). 2020 Open Access This article is licensed under a Creative Commons Attribution 4.0 International License, which permits use, sharing, adaptation, distribution and reproduction in any medium or format, as long as you give appropriate credit to the original author(s) and the source, provide a link to the Creative Commons licence, and indicate if changes were made. The images or other third party material in this article are included in the article's Creative Commons licence, unless indicated otherwise in a credit line to the material. If material is not included in the article's Creative Commons licence and your intended use is not permitted by statutory regulation or exceeds the permitted use, you will need to obtain permission directly from the copyright holder. To view a copy of this licence, visit http://creativecommons.org/licenses/by/4.0/ The Creative Commons Public Domain Dedication waiver (http://creativecommons.org/publicdomain/zero/1.0/) applies to the data made available in this article, unless otherwise stated in a credit line to the data. 


\section{Background}

Intraductal papillary mucinous neoplasms (IPMNs) were first defined by Ohashi et al. in 1982 as rare papillary pancreatic neoplasms arising from major pancreatic ducts, characterized by duct dilation and mucin secretion [1]. They comprise approximately $1 \%$ of all exocrine neoplasms, and they are more common in older men. These neoplasms are usually asymptomatic in early stages, but multiple cases present with recurrent episodes of pancreatitis, in addition to diabetes and steatorrhea due to pancreatic insufficiency [2].

They are primarily classified as main duct-type (MDIPMN), branch duct-type (BD-IPMN), and mixed-type IPMN, which is defined as the anatomic combination of both types [3-5]. Also, histological classification depending on the epithelial cells includes gastric, intestinal, pancreatobiliary, and oncocytic subtypes $[2,3,6]$. Herein, we report the case of a 70-year-old woman who was diagnosed with a mixed-type IPMN with a rare combination of gastric and pancreatobiliary subtypes.

\section{Case presentation}

A 70-year-old Syrian woman presented to the gastroenterology department of our hospital in March 2019 due to an intermittent localized epigastric pain for 10 days accompanied by diarrhea, nausea, and weight loss with no fever. Her blood pressure and electrocardiogram results were normal during physical examination., Six days previously, our patient had noticed that her urine was a dark color.

Her medical and surgical history mentioned a recent diagnosis of type 2 diabetes mellitus during a routine check-up examination only 25 days prior to the initial presentation, in addition to a history of a partial thyroidectomy 20 years ago and hip replacement surgery 7 years ago. Her family history included a diagnosis of type 2 diabetes mellitus in her father and brother, while her psychosocial history was unremarkable. Additional files and details of our patient's surgical history and previous medical investigations before presentation to our institution were not available.

On initial presentation to our hospital, a blood test revealed a white blood cell (WBC) count of $5 \times 10^{3} / \mathrm{UL}$, a lymphocyte count of $47 \%$, a neutrophil count of $50 \%$, hemoglobin value of $13.2 \mathrm{~g} / \mathrm{dl}$, total bilirubin of $0.8 \mathrm{mg} /$ $\mathrm{dl}$, direct bilirubin of $0.3 \mathrm{mg} / \mathrm{dl}$, amylase of $42 \mathrm{U} / \mathrm{L}$, glucose value of $237 \mathrm{mg} / \mathrm{dl}$, and C-reactive protein (CRP) value of 120 . In addition, her thyroid-stimulating hormone (TSH) value was determined to be $8.22 \mathrm{u} \mathrm{IU} / \mathrm{m}$ (reference range $0.38-4.31 \mathrm{u} \mathrm{IU} / \mathrm{ml}$ ), with normal values of free thyroxine (FT4) and free triiodothyronine (FT3).

An abdominal ultrasound revealed a cystic dilation in the main pancreatic duct across the body of the pancreas, and involved an irregular-shaped mass (Fig. 1).

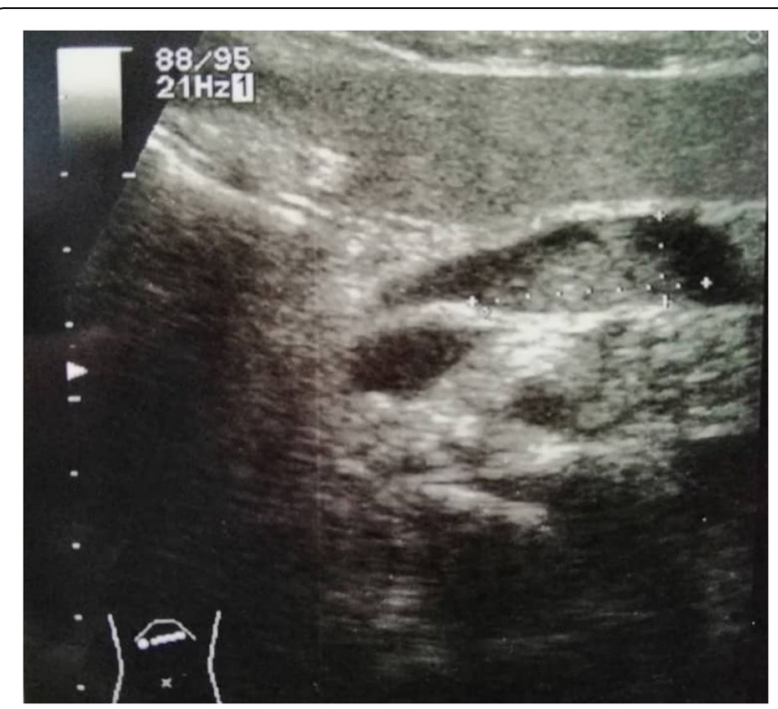

Fig. 1 Abdominal ultrasound revealing a cystic dilation in the main pancreatic duct

Endoscopic retrograde cholangiopancreatography (ERCP) demonstrated a fish-mouth appearance of the ampulla of Vater, which was catheterized by bioptome, and revealed a $15 \mathrm{~mm}$ cystic dilation in the main duct surrounding an irregular-shaped mucinous lesion in the connection point between the head and the body of the pancreas, and connected laterally to multiple small cleftlike cysts in the smaller branch ducts (Fig. 2). The primary differential diagnosis according to the radiological

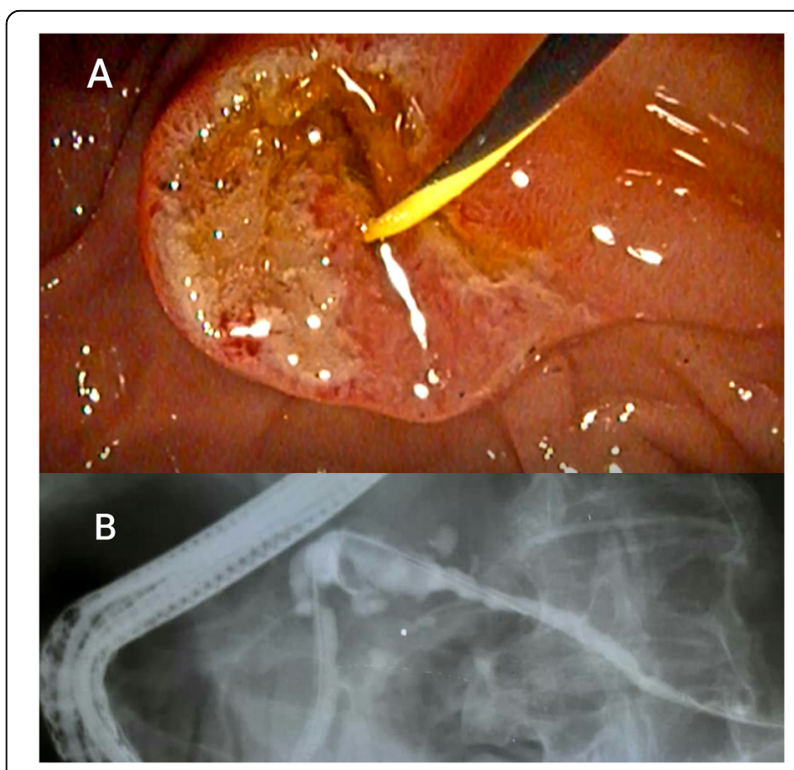

Fig. 2 a Endoscopic retrograde cholangiopancreatography (ERCP) demonstrating a cystic dilation in the main duct surrounding an irregular-shaped mucinous lesion that was catheterized by bioptome. $\mathbf{b}$ X-ray image during ERCP. ERCP endoscopic retrograde cholangiopancreatography 
findings included intraductal papillary mucinous neoplasm (IPMN) and mucinous cystic neoplasm (MCN), and our patient was then referred to the surgical department and scheduled for a surgical operation. Two days later, our patient underwent distal pancreatectomy involving the body and the tail of the pancreas in addition to a cholecystectomy. The resected specimens consisted of multiple fragmented pieces of tissue from the intrapancreatic duct tumor, in addition to multiple pieces labeled as proximal margins, the gallbladder, and a piece of pancreatic tissue. The histological examination of the tumor revealed complex branching papillae lined by $\mathrm{cu}-$ boidal cells with moderate amphophilic cytoplasm and enlarged hyperchromatic nuclei resembling cholangiopapillary epithelium with intermediate-grade dysplasia, in addition to short thick papillae lined by mucinproducing columnar cells with eosinophilic cytoplasm and basally located nuclei with low-grade dysplasia resembling gastric foveolae (Figs. 3 and 4). Immunohistochemical (IHC) stainings revealed high positivity for epithelial membrane antigen (EMA) and cytokeratin 7 (CK7), with weak positivity for cytokeratin 20 (CK20) (Fig. 5). However, the aforementioned IHC markers are considered general markers of ductal epithelial cells and unfortunately, additional ancillary techniques including molecular and additional IHC markers were not available in our pathology lab.

Nevertheless, based on detailed examination of the radiological and morphological features with multiple pathological and radiological consultations, the diagnosis was confirmed as a low-grade mixed-type IPMN with a mixed histological combination of gastric and pancreatobiliary subtypes. The rest of the pancreatic tissue was diagnosed as chronic pancreatitis. Although the admitted specimens included pieces of tissue labeled as proximal

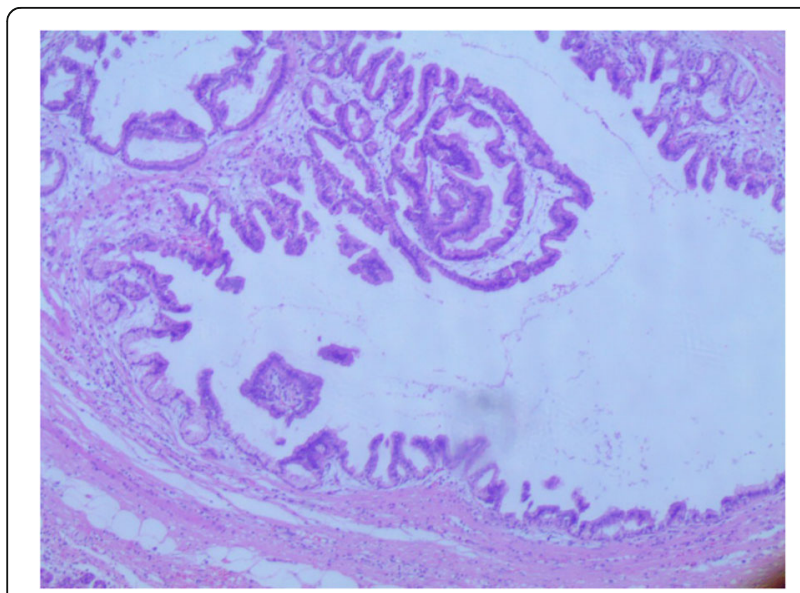

Fig. 3 Morphologic features of both pancreatobiliary epithelium (upper left) and gastric epithelium (lower right) (hematoxylin and eosin (H\&E) stain, original magnification $\times 200$ ). H\&E hematoxylin and eosin

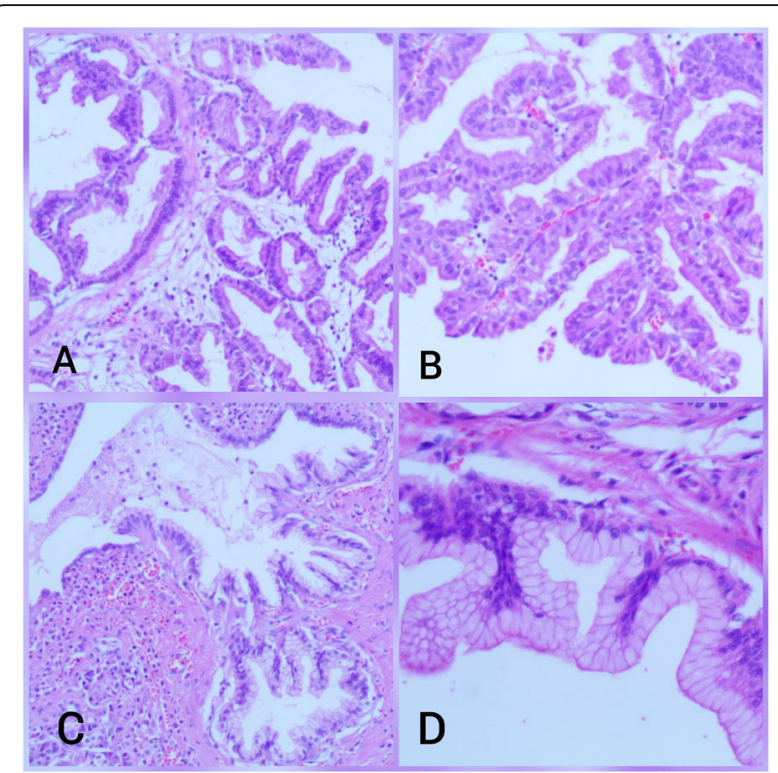

Fig. 4 a and $\mathbf{b}$ Complex branching papillae lined by cuboidal cells with moderate amphophilic cytoplasm and hyperchromatic nuclei, demonstrating morphological features of pancreatobiliary epithelium. c and $\mathbf{d}$ Short papillae lined by columnar cells with eosinophilic cytoplasm and basally located nuclei, demonstrating morphological features of gastric epithelium. (hematoxylin and eosin (H\&E) stain, a original magnification $\times 200$, $\mathbf{b}$ original magnification $\times 400$, c original magnification $\times 200$, d original magnification $\times 600$ ). H\&E hematoxylin and eosin

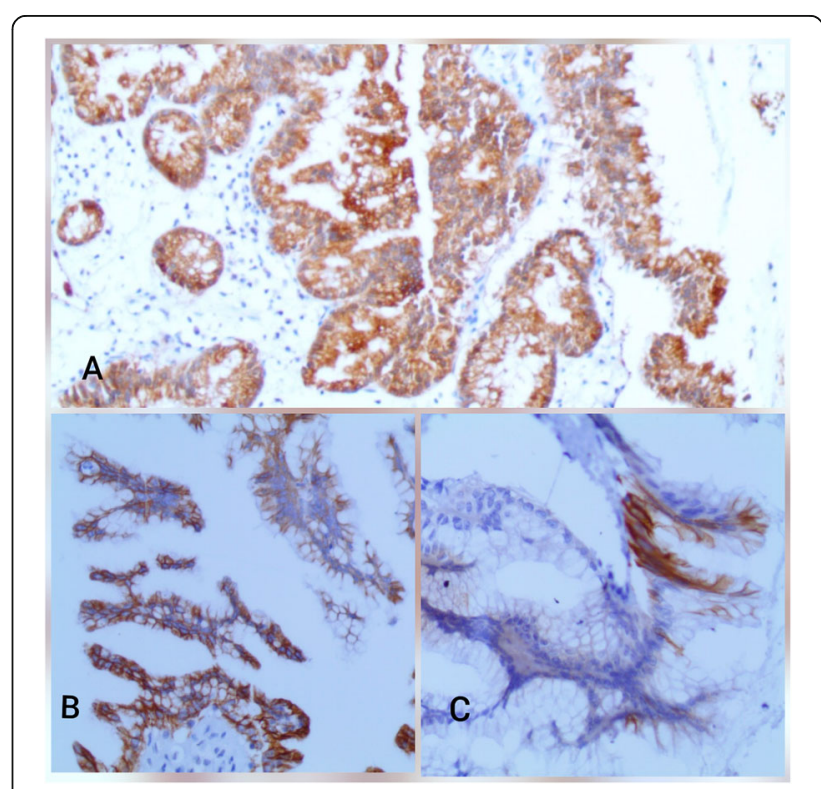

Fig. 5 Immunohistochemistry (IHC) of the neoplasm. a High positivity for EMA. b High positivity for CK7. c Low positivity for CK20. CK cytokeratin, EMA epithelial membrane antigen,

IHC immunohistochemistry 
margins according to the surgical report, margins status could not be assessed by the pathologist due to the fragmentation of the specimens. Nevertheless, there was no evidence of high-grade dysplasia or malignancy. A whole-body computed tomography (CT) scan revealed no suspected lesions in her other organs. After the surgery, blood tests revealed lymphopenia, anisocytosis, high levels of CRP and serum glucose. However, our patient's test results, except for glucose and TSH, went back to normal 5 days later. No adjuvant therapy was recommended, and our patient was put on levothyroxine (Eltroxin) (due to the high level of TSH), and insulin (Mixtard). According to the monthly blood test results, her TSH levels went back to normal 5 months later, while a moderate elevation in glucose value is still being reported (ranging between 203 and $245 \mathrm{mg} / \mathrm{dl}$ up to the time of reporting this case).

Furthermore, ultrasonographic monitoring every 6 months was recommended. From the surgical procedure until her last visit in March 2020, our patient has been in a stable condition. A timeline of our patient's case can be seen in Fig. 6.

\section{Discussion}

IPMNs comprise approximately $21-41 \%$ of pancreatic cystic neoplasms and 1-3\% of all pancreatic exocrine neoplasms. Although the exact incidence is still unknown due to the absence of symptoms in most cases
[2, 3], some patients report atypical symptoms including epigastric pain, weight loss, nausea, vomiting, and jaundice. The majority of cases have been reported as benign with a predominance in 60-70-year-old men [3, 4]. However, our case was symptomatic and reported in a 70-year-old woman.

Many risk factors have been shown to increase the incidence of these neoplasms including diabetes mellitus, as in our case, chronic pancreatitis, family history of pancreatic ductal adenocarcinoma, and mutations in GNAS and KRAS genes. Interestingly, smoking is not reported as a risk factor although it can induce malignancy in IPMNs [5].

According to their anatomical sites, IPMNs are classified into main duct-type (MD-IPMN), which has a higher risk of malignancy, branch duct-type (BD-IPMN), which is associated with multifocal cystic lesions, and mixed-type IPMN, which is a combination of both types [3]. As our case demonstrated a cystic dilation involving the main duct and connected to multiple small cleft-like cysts, the diagnosis was a mixed-type IPMN.

While IPMNs might be accompanied by extrapancreatic malignant tumors involving the breast, lungs, prostate, colon, and rectum [3-5], CT scan and ultrasound scanning were free of any additional neoplasms in our patient.

Abdominal CT scan has been historically considered the most common radiological method used in

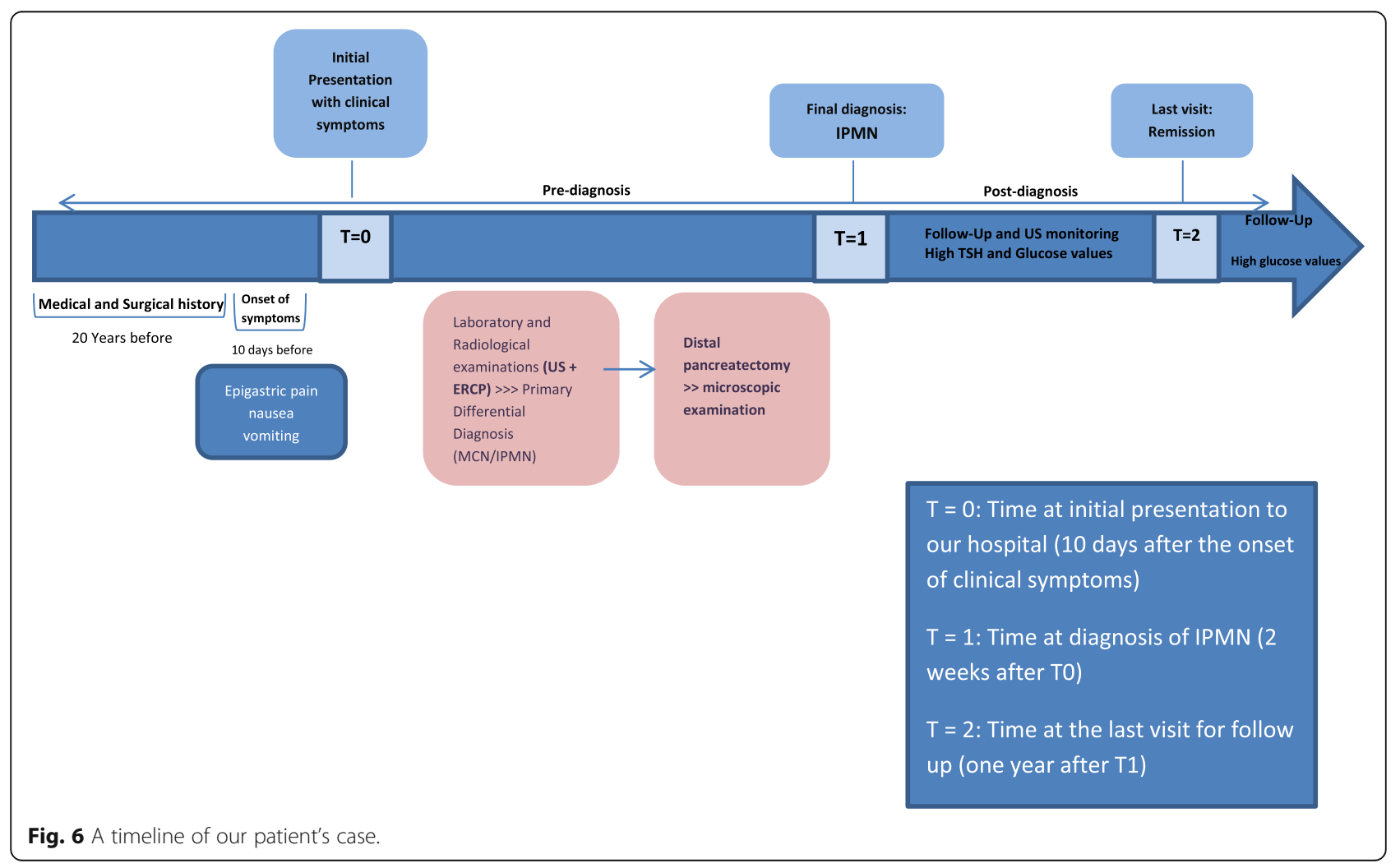


diagnosing IPMN. However, ERCP is considered more reliable for early diagnosis and demonstrating detailed features of the ductal system [6, 7]. In our patient, ERCP enabled us to determine the anatomical type of the neoplasm and the size of the cystic dilation, which referred to a higher risk of malignancy.

Studies reveal that both CT and magnetic resonance imaging have equal accuracy in staging malignancy of pancreatic ductal neoplasms $[6,8]$, Magnetic resonance cholangiopancreatography (MRCP) appears to have more sensitivity than ERCP to demonstrate internal septations and multiple focal cysts according to International Consensus Guidelines 2012 [8], it is also recommended to be used in the follow-up. Also, endoscopic ultrasound (EUS) elastography and confocal laser endomicroscopy are new methods to diagnose IPMNs but need further evaluation before putting in use $[6,7,9]$.

Furthermore, EUS is highly preferable as an imaging method for pancreatic cystic neoplasms as it can distinguish IPMNs anatomical types, and demonstrate features of suspected malignancy, in addition to the ability to perform a guided fine-needle aspiration for further evaluation [9].

Histologically, a considerable heterogeneity is noticed in the epithelium by identifying four histological subtypes of the precursor component: Gastric subtype, which is characterized by thick short papillae lined by columnar cells with eosinophilic cytoplasm, basally located nuclei, and strong positivity for MUC5AC. This subtype represents the most common subtype and is usually associated with the BD-type in contrast to our case. Other histological subtypes include the intestinal subtype, which is usually associated with the MD-type and resembles intestinal villous neoplasms with columnar cells, pseudostratified hyperchromatic nuclei and strong positivity for MUC2; pancreatobiliary subtype, which is a rare subtype characterized by complex papillae lined by cuboidal cells with amphophilic cytoplasm, hyperchromatic nuclei, marked atypia, and strong positivity for MUC1; and oncocytic subtype, which presents with branching papillae lined by oncocytic cells with intracellular lumina and focal positivity for MUC1 [1012]. Interestingly, although the oncocytic subtype is considered a histological subtype of IPMNs according to the World Health Organization classification of pancreatic tumors in 2010 [13], recent studies suggest defining it as a separate type due to distinct morphological and molecular features [14].

Nevertheless, our case showed a rare combination of gastric and pancreatobiliary subtypes in a mixed-type IPMN that was diagnosed based on assessing morphological features with hematoxylin and eosin (H\&E) stainings only due to economic restrictions, as the aforementioned IHC stainings were not available.
Despite the above, at the current time, it is not likely that histological subtypes have an influence on decided clinical management in non-invasive neoplasms like in our case, while they have a significant prognostic implication in invasive carcinoma $[10,11]$.

Differential diagnosis includes many lesions, most commonly are MCNs, serous cystadenoma, pseudocysts, and chronic pancreatitis. Many factors play a crucial role in establishing the diagnosis including the age of the patient, radiological findings, clinical presentation, anatomical location, and morphological features [15].

MCNs are spherical cysts with peripheral calcifications, an ovarian-type stroma, and variable-thickened septations. They are more common in young women, and they usually arise in the body and the tail of the pancreas without connecting to the ductal system.

Serous cystadenomas tend to affect older women and they are usually located in the head of the pancreas accompanied by multiple microcysts with a honeycomblike pattern, central calcification, a thin peripheral wall, and a non-mucinous clear fluid. Also, the absence of septations, mural nodules and the lack of an epithelial lining, as well as the presence of necrotic hemorrhagic debris increases the possibility of pseudocysts $[15,16]$. Regarding our case, the absence of ovarian-type stroma, and the connection to the ductal system of a mucinous neoplasm in an older patient in addition to other radiological and morphological features were all crucial clues to support the diagnosis.

Genetically, next-generation sequencing revealed that the presence of IPMNs correlates with multiple genetic mutations including GNAS mutations, which are considered the most common and specific alteration in this neoplasm. Also, an activation in G-protein signaling seems to be associated with the progression of IPMNs, while the expression of phosphorylated substrates of protein kinase A contributes to the pathological grade of this neoplasm [17].

Regarding surgical recommendations, researchers have different points of view toward IPMN enucleation because, on one hand, it can preserve the pancreatic function for a long time as most of the parenchyma is preserved. On the other side, cysts may be ruptured during the procedure, which leads to peritoneal seeding. Furthermore, postoperative complications like pancreatic fistula are commonly noticed. Thus, regional pancreatectomy as a curative procedure is the main challenge, and researchers have discussed frozen section analysis as an important component of the surgery $[18,19]$. Thus, it is crucial to select the ideal procedure for non-invasive IPMNs considering short- and long-term results, in addition to postoperative complications.

International guidelines for IPMNs treatment include pancreaticoduodenectomy, distal pancreatectomy, or 
total pancreatectomy with lymph node segmentation and malignancy-free margins $[19,20]$.

Overall, invasive IPMNs were found to have the best response to pancreaticoduodenectomy, while noninvasive IPMNs of the body and the tail respond to distal pancreatectomy, and finally, patients with diffused IPMNs or IPMNs that extend through the body and tail undergo total pancreatectomy [19, 20]. As our patient was diagnosed with a non-invasive low-grade IPMN, distal pancreatectomy involving the body and the tail of the pancreas was reliable. Unfortunately, fragmentation of the resected specimen prevented accurate assessing of margins status.

One study revealed that invasive IPMNs have recurrence rates of almost $67-91 \%$ with a 5 -year survival rate of $40-60 \%$, while non-invasive IPMNs are found to have almost no recurrence with a survival rate up to approximately $100 \%[11,19,20]$. Our patient has been in a stable condition with no detected recurrence so far. However, as she has been diagnosed with the mixedtype IPMN, which has a higher risk than BD-IPMN of transforming into malignancy, in addition to the presence of multiple risk factors including the large dilation of the main duct $(>1 \mathrm{~cm})$ and the symptoms of jaundice and diabetes; surgical resection followed by regular monitoring is essential $[6,20]$.

\section{Conclusions}

In conclusion, our case demonstrated a rare histological combination that represented a hard diagnostic challenge due to the difficulties in differential diagnosis and the lack of proper immunohistochemical and molecular techniques. However, with clinical correlation, accurate observation of radiological and morphological findings, as well as reliable surgical management, we were able to confirm the diagnosis.

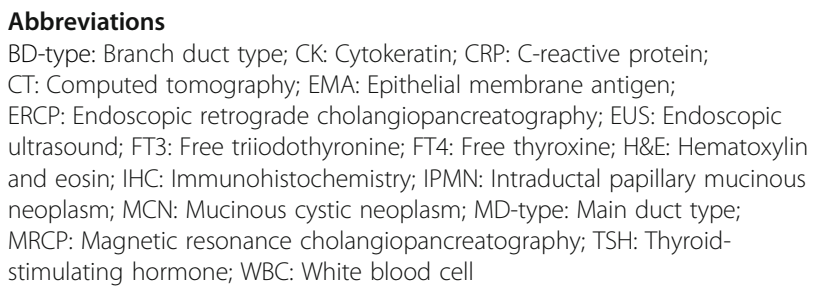

\section{Acknowledgements}

The authors would like to thank Dr. Samir Kanaan and Dr. Maher Madi from Tishreen University Hospital, Lattakia, Syria.

\section{Authors' contributions}

SI drafted the manuscript and collected the patient's data. RD and MA participated in collecting the data and drafting the manuscript. $\mathrm{MH}$ performed the surgical operation, provided the patient's data, and participated in revising the manuscript. MAH performed the pathologic examination and participated in revising the manuscript. ZA The supervisor and guarantor, critically revised the manuscript, approved the final draft and participated in the pathologic examination. The author(s) read and approved the final manuscript.

\section{Authors' information}

$\mathrm{SI}$ is a pathology resident and master's student. RD is a nephrology resident and master's student. MA is an obstetrics and gynecology resident and master's student. MH is a general surgeon. MAH and ZA are professors of pathology.

\section{Funding}

Not applicable.

\section{Availability of data and materials \\ Not applicable.}

\section{Ethics approval and consent to participate} Not applicable.

\section{Consent for publication}

Written informed consent was obtained from the patient for publication of this case report and any accompanying images. A copy of the written consent is available for review by the Editor-in-Chief of this journal.

\section{Competing interests}

The authors declare that they have no competing interests.

\section{Author details}

'Department of Pathology, Cancer Research Center, Faculty of Medicine, Tishreen University, Lattakia, Syria. ${ }^{2}$ Department of Nephrology, Tishreen University Hospital, Lattakia, Syria. ${ }^{3}$ Department of Obstetrics and Gynecology, Tishreen University Hospital, Lattakia, Syria. ${ }^{4}$ Department of General Surgery, Tishreen University Hospital, Lattakia, Syria. ${ }^{5}$ Faculty of Pharmacy, Al-Sham Private University, Lattakia, Syria.

Received: 21 April 2020 Accepted: 27 July 2020

Published online: 09 September 2020

\section{References}

1. Ohashi K, Murakami Y, Takekoshi T. Four cases of mucin producing cancer of the pancreas on specific findings of the papilla of Vater. Prof Dig Endosc. 1982;20:348-51.

2. Fonseca AL, Kirkwood K, Kim MP, Maitra A, Koay EJ. Intraductal papillary mucinous neoplasms of the pancreas: current understanding and future directions for stratification of malignancy risk. Pancreas. 2018;47(3):272-9.

3. Kloppel G, Solcia E, Longnecker DS, Capella C, Sobin LH. World Health Organization international histologic typing of tumors of the exocrine pancreas. In: Classifications of tumors. Berlin: Springer; 1996. p. 11-20.

4. Morales-Oyarvide V, Fong ZV, Fernández-Del Castillo C, Warshaw AL. Intraductal papillary mucinous neoplasms of the pancreas: strategic considerations. Visc Med. 2017;33(6):466-76.

5. Aronsson L, Andersson R, Ansari D. Intraductal papillary mucinous neoplasm of the pancreas - epidemiology, risk factors, diagnosis, and management. Scand J Gastroenterol. 2017;52(8):803-15.

6. Machado NO, Al Qadhi H, Al Wahibi K. Intraductal papillary mucinous neoplasm of pancreas. N Am J Med Sci. 2015;7(5):160-75.

7. Vilas-Boas F, Macedo G. Management guidelines for pancreatic cystic lesions: should we adopt or adapt the current roadmaps? J Gastrointestin Liver Dis. 2019;28(4):495-501.

8. Tanaka M, Fernández-del Castello C, Adsay V, Chari S, Falconi M, et al. International Association of Pancreatology. International consensus guidelines 2012 for the management of IPMN and MCN of the pancreas. Pancreatology. 2012;12:183-97.

9. Efthymiou A, Podas T, Zacharakis E. Endoscopic ultrasound in the diagnosis of pancreatic intraductal papillary mucinous neoplasms. World J Gastroenterol. 2014;20(24):7785-93.

10. Furukawa T, Klöppel G, Volkan Adsay N, Albores-Saavedra J, Fukushima N, Horii A, et al. Classification of types of intraductal papillary-mucinous neoplasm of the pancreas: a consensus study. Virchows Arch. 2005;447(5): 794-9.

11. Rong $Y$, Wang $D, X u C$, Ji $Y$, Jin $D$, Wu W, et al. Prognostic value of histological subtype in intraductal papillary mucinous neoplasm of the pancreas: a retrospective analysis of outcome from one single center. Medicine (Baltimore). 2017;96(15):e6599. 
12. Adsay NV, Merati K, Basturk O, lacobuzio-Donahue C, Levi E, Cheng JD, et al. Pathologically and biologically distinct types of epithelium in intraductal papillary mucinous neoplasms: delineation of an "intestinal" pathway of carcinogenesis in the pancreas. Am J Surg Pathol. 2004;28:839-48.

13. Adsay NV, Kloppel G, Fukushima N, Hruban RH, Klimstra DS, Klöppel G, et al. Intraductal neoplasms of the pancreas. In: Bosman FT, Carneiro F, Hruban RH, Theise ND, editors. WHO classification of tumors. Lyon: IARC Press; 2010. p. 304-13.

14. Basturk O, Tan M, Bhanot U, Allen P, Adsay V, Scott SN, et al. The oncocytic subtype is genetically distinct from other pancreatic intraductal papillary mucinous neoplasm subtypes. Mod Pathol. 2016;29:1058-69.

15. Cunningham SC, Hruban RH, Schulick RD. Differentiating intraductal papillary mucinous neoplasms from other pancreatic cystic lesions. World J Gastrointest Surg. 2010;2(10):331-6.

16. Lévy P, Rebours V. Differential diagnosis of cystic pancreatic lesions including the usefulness of biomarkers. Viszeralmedizin. 2015;31(1):7-13.

17. Furukawa T, Kuboki Y, Tanji E, Yoshida S, Hatori T, Yamamoto M, et al. Whole-exome sequencing uncovers frequent GNAS mutations in intraductal papillary mucinous neoplasms of the pancreas. Sci Rep. 2011;1:161.

18. Aunan JR, Jamieson NB, Søreide K. Observation or resection of pancreatic intraductal papillary mucinous neoplasm: an ongoing tug of war. World J Gastrointest Oncol. 2019;11(12):1092-100.

19. Hirono S, Yamaue H. Surgical strategy for intraductal papillary mucinous neoplasms of the pancreas. Surg Today. 2020;50(1):50-5.

20. European Study Group on Cystic Tumours of the Pancreas. European evidence-based quidelines on pancreatic cystic neoplasms. Gut. 2018;67(5): 789-804.

\section{Publisher's Note}

Springer Nature remains neutral with regard to jurisdictional claims in published maps and institutional affiliations.

Ready to submit your research? Choose BMC and benefit from:

- fast, convenient online submission

- thorough peer review by experienced researchers in your field

- rapid publication on acceptance

- support for research data, including large and complex data types

- gold Open Access which fosters wider collaboration and increased citations

- maximum visibility for your research: over $100 \mathrm{M}$ website views per year

At $\mathrm{BMC}$, research is always in progress.

Learn more biomedcentral.com/submissions 